\title{
HIV-related sexual risk behaviour between 1996 and 2008, according to age, among men who have sex with men (Scotland)
}

\author{
Christina Knussen, ${ }^{1}$ Paul Flowers, ${ }^{1}$ Lisa M McDaid, ${ }^{2}$ Graham $\mathrm{J} \mathrm{Hart}^{3}$
}

'Department of Psychology, Glasgow Caledonian University, Glasgow, UK

${ }^{2} \mathrm{MRC} / \mathrm{CSO}$ Social and Public Health Sciences Unit, Glasgow, UK

${ }^{3}$ Centre for Sexual Health and HIV Research, Research Department of Infection and Population Health, University College London, London, UK

\section{Correspondence to}

Dr C Knussen, Department of Psychology, Glasgow Caledonian University, Glasgow G4 OBA, UK;

c.knussen@gcu.ac.uk

Accepted 7 October 2010

Published Online First

11 November 2010

\section{ABSTRACT \\ Objective To examine changes in the proportions of those reporting $2+$ unprotected anal intercourse (UAI) partners in the previous 12 months among men who have sex with men (MSM) in Scotland between 1996 and 2008. Differences according to age group were also examined.}

Methods Logistic regression was used with data from eight cross-sectional anonymous, self-report surveys in commercial gay venues in Glasgow and Edinburgh $(\mathrm{N}=10223)$. Data were stratified according to survey and age group ( $<25$ years vs $\geq 25$ years).

Results The percentage of $2+$ UAl partners reported in the previous 12 months increased significantly between 2000 and 2002, adjusted for age group. When the surveys were divided into two time periods (1996-2000 and 2002-2008), no significant differences were found within each time period in the percentage of $2+\mathrm{UAl}$ partners reported (adjusted for age group). However, a significant increase was found when the aggregated figures for 2002-2008 were compared with those for 1996-2000. At the aggregate level, those aged $<25$ years were significantly more likely than those aged $\geq 25$ years to report $2+$ UAl partners in the previous 12 months (adjusted for survey).

Conclusions HIV-related sexual risk behaviour did not change significantly between 2002 and 2008 among MSM in Scotland, after the increases noted between 2000 and 2002. A significant minority of MSM continue to engage in relatively high levels of sexual risk, and younger generations appear to be at particular risk. This represents a public health concern and highlights the need for targeted age-specific interventions.

\section{INTRODUCTION}

In the UK, men who have sex with men (MSM) are the group most at risk of acquiring $\mathrm{HIV}^{1}$ and an emphasis on prevention efforts is a key policy recommendation. ${ }^{1} 2$ There has been growing international concern regarding increasing rates of unprotected anal intercourse (UAI) and HIV notifications in populations of MSM across the developed world. ${ }^{3}$ Increased sexual risk behaviour was observed among gay men in Scotland in 2002, ${ }^{4}$ with indications of age-related differences ${ }^{4}{ }^{5}$; given the implications of age for targeting prevention efforts, this was deemed worthy of further investigation. Here, we examine HIV-related sexual risk behaviour $(2+$ UAI partners in the previous 12 months) according to age group using data from eight surveys conducted between 1996 and 2008 in Glasgow and Edinburgh.

\section{METHODS}

Eight cross-sectional surveys (anonymous and selfreport) were conducted between 1996 and 2008 in commercial gay venues in Glasgow and Edinburgh. ${ }^{5}$ The same time and location sampling strategies were used in every survey. ${ }^{4}$ Two variables are included in the analysis: age $(<25$ years vs $\geq 25$ years) and number of UAI partners in the previous 12 months (0/1 UAI partner vs $2+$ UAI partners). Although the content of the surveys varied somewhat according to changing objectives over time, the wording of the question on UAI partners was identical in all surveys. Ethical approval was granted by the University of Glasgow Ethics Committee for Non-clinical Research Involving Human Subjects, University of Glasgow Faculty of Medicine Ethics Committee or the Psychology Ethics Committee at Glasgow Caledonian University.

The analysis was conducted using SPSS 16.0 for Mac. The proportions of those reporting 2+ UAI partners within the previous 12 months were stratified by age group and by survey. Using binary logistic regression with UAI category as the dependent variable, each survey was compared with the next (starting with the earliest) to examine change over time, adjusted for age group. The data from three of the surveys were combined (2002a, 2002b and 2003). A comparison was then made between 1996-2000 and 2002-2008 (adjusted for age group) in the reporting of $2+$ UAI partners: this cutoff point was chosen following examination of the results of the first analysis. Finally, differences between the two age groups in rates of $2+$ UAI partners were examined, adjusted for survey. For significant differences according to time and/or age group, estimated adjusted odds ratios (AOR), 95\% CI (CI) and p-values are reported.

\section{RESULTS}

The total number of participants across all eight surveys was 11121 , with an average response rate of $70 \%$ (range $62-79 \%$ ). Men responding to the questions on age and number of UAI partners in the previous 12 months were included in the analysis $(\mathrm{N}=10223)$. UAI partners in the previous 12 months $(0 / 1$ vs $2+$ ) were examined over time and by age group. The proportions of those in the two age groups varied significantly according to survey $(p<0.001)$, underlining the necessity of adjusting for age group in all analyses. No significant differences were found in the percentages of $2+$ UAI partners among the two surveys conducted in 2002 and that conducted in 2003: the samples unlocked scheme, see http://sti. bmi.com/site/about/unlocked. xhtml 


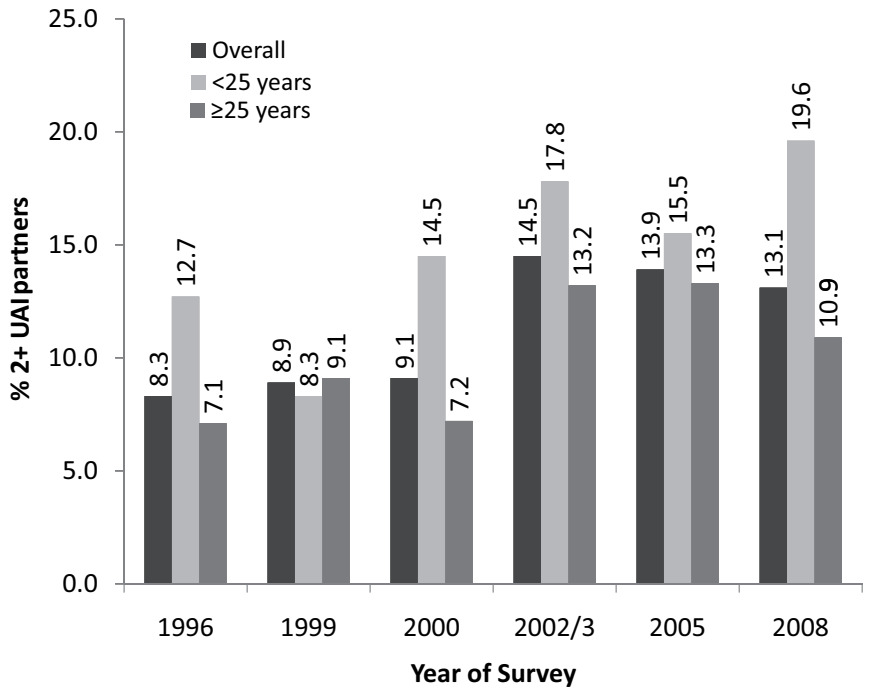

Figure 1 Percentages of those reporting 2+ UAI partners within the previous 12 months over time and by age group $(<25$ years and $\geq 25$ years).

Notes: $2+$ UAl partners $=2$ or more unprotected anal intercourse partners within previous 12 months. Key to surveys (year, funder, location, $\mathrm{n}$ ).

1996: MRC, Edinburgh/Glasgow, $\mathrm{n}=2184$.

1999: MRC, Edinburgh/Glasgow, $\mathrm{n}=2244$.

2000: Healthy Gay Scotland, Edinburgh/Glasgow, $n=713$.

2002/3 (total $n=2106$ ): 2002a) MRC, Edinburgh/Glasgow, $n=1573$;

2002b) Gay Men's Health, Edinburgh, $n=276 ;$ 2003, Gay Men's Health, Edinburgh, $\mathrm{n}=257$.

2005: MRC, Edinburgh/Glasgow, $\mathrm{n}=1646$.

2008: $M R C, E d i n b u r g h / G l a s g o w, ~ n=1330$. Odds ratios adjusted for age group (AOR) of 2+ UAl partners for consecutive surveys (i.e., comparing each survey with previous survey);

1996-1999: AOR 0.93, 95\% Cl 0.75 to $1.15, \mathrm{p}=0.498$.

1999-2000: AOR $0.98,95 \% \mathrm{Cl} 0.73$ to $1.32, \mathrm{p}=0.897$.

2000-2002/3: AOR 1.68, 95\% Cl 1.26 to $2.23, \mathrm{p}<0.001$.

2002/3-2005: AOR 1.05, 95\% Cl 0.87 to $1.26, p=0.628$.

2005-2008: AOR 1.06, 95\% Cl 0.86 to $1.32, \mathrm{p}=0.567$.

(two of which were small) were therefore combined. Figure 1 shows the percentages of those reporting 2+ UAI partners within each year, by age group. The results of the comparisons between consecutive surveys are also shown.

The percentage of $2+$ UAI partners reported in the previous 12 months increased significantly between 2000 and 2002. No other significant differences in the percentages of $2+$ UAI partners were found between consecutive surveys. The surveys were then divided into two time periods: 1996-2000 and 2002-2008. No significant differences were found within each time period in the percentage of $2+$ UAI partners, but a significant increase was found when the aggregated data for 2002-2008 were compared with those for 1996-2000: AOR 1.675, 95\% CI 1.48 to 1.90 , $\mathrm{p}<0.001$. It should also be noted that a significant difference in the proportions of those in the two age groups was also found at this stage $(p<0.001)$ : the proportion of those aged $<25$ years increased from $23.0 \%$ to $26.6 \%$. With regard to age, at the aggregate level, those aged $<25$ years were significantly more likely than those aged $\geq 25$ years to report $2+$ UAI partners in the previous 12 months: AOR 1.45, 95\% CI 1.27 to $1.66, \mathrm{p}<0.001$

\section{DISCUSSION}

Although HIV-related sexual risk behaviour increased among MSM in Scotland between 2000 and 2002, our analysis suggests

\section{Key messages}

HIV-related sexual risk behaviour increased among MSM in Scotland between 2000 and 2002, but did not increase between 2002 and 2008.

- A significant minority of MSM continue to engage in relatively high levels of sexual risk behaviour.

- Age-related differences in sexual risk behaviour suggest that intensive, targeted prevention work is required, addressing younger generations of MSM.

that, at the population level, sexual risk behaviour was stable between 2002 and 2008. This conclusion is reflected elsewhere, albeit using different populations and measures of risk behaviour. ${ }^{7}$ The increase between 2000 and 2002 is perhaps consistent with a reported increase of HIV notifications between 2000 and $2005 .^{8}$ The findings highlight the need to examine further the mechanisms of community-level change and details of risk behaviour within particular subpopulations, ${ }^{9}{ }^{10}$ in addition to the monitoring of community level data over time. Moreover, the data suggest the value of tracking individual sexual careers within changing contexts. HIV-related attrition no longer removes those engaging in HIV-related behaviour from the sexually active population of MSM. As our data do not show a trend of increasing levels of UAI across time, there could be cause for interpreting the plateau in observed risk behaviour as indicative of some success in prevention efforts. However, the findings highlight significant on-going levels of sexual risk and, episodically, age-related vulnerabilities.

The analysis was limited to some extent by lack of information on UAI partners and on the frequency of patronising recruitment venues, and by a failure to record city of recruitment at respondent level in one of the surveys. Despite such limitations, it would appear that there is an on-going need for both population-based and targeted HIV prevention. While it is acknowledged that age-related differences may hide more complex patterns of behaviour, ${ }^{10}$ our findings highlight the need to target the younger generations of MSM who are reporting higher levels of risk behaviour.

Acknowledgements We thank the survey staff and fieldworkers in each city, the venue managers, their staff and the men who agreed to participate in the survey. We thank Gay Men's Health and Healthy Gay Scotland for the sharing of their data. Finally, we thank the reviewers of the first draft of this paper for their helpful and generous comments

Funding Medical Research CouncilHIV ScotlandGay Men's Health. The UK Medical Research Council funds LMcD and the 1996, 1999, 2002a, 2005 and 2008 surveys as part of the Sexual and Reproductive Health Programme (WBS U.1300.00.005) at the Social and Public Health Sciences Unit. HIV Scotland funded the Healthy Gay Scotland 2000 survey and Gay Men's Health funded the 2002b and 2003 surveys.

\section{Competing interests None.}

Ethics approval This study was conducted with the approval of the University of Glasgow Ethics Committee for Non-clinical Research Involving Human Subjects, University of Glasgow Faculty of Medicine Ethics Committee, or the Psychology Ethics Committee at Glasgow Caledonian University.

Contributors PF, CK and $\mathrm{LMCD}$ devised the paper. CK conducted the analysis and wrote the first draft. All authors contributed to subsequent drafts and approved the final version of the manuscript.

Provenance and peer review Not commissioned; externally peer reviewed.

\section{REFERENCES}

1. Health Protection Agency. HIV in the United Kingdom: 2009 Report. London: Health Protection Agency, 2009. 
2. Scottish Government. HIV Action Plan in Scotland December 2009-March 2014 Edinburgh: Scottish Government, 2009. http://www.scotland.gov.uk/Publications/ 2009/11/24105426/0 (accessed 22 Mar 2010).

3. Hart GJ, Elford J. Sexual risk behaviour of men who have sex with men: emerging patterns and new challenges. Curr Opin Infect Dis 2010;23:39-44.

4. Hart GJ, Williamson LM. Increase in HIV sexual risk behaviour in homosexual men in Scotland, 1996-2002: prevention failure? Sex Transm Infect 2005;81:367-72.

5. Williamson LM, Flowers $\mathrm{P}$, Knussen C, et al. HIV testing trends among gay men in Scotland, UK (1996-2005): implications for HIV testing policies and prevention. Sex Transm Infect 2009; 85:550-4

6. Lattimore S, Thornton A, Delpech V, et al. Trends in sexual risk behaviour among London gay men between 1998 and 2008(OS1.2.04). 18th International Society for STD Research Conference. London, UK: 2009.
7. Crepaz N, Marks G, Liau A, et al. Prevalence of unprotected anal intercourse among HIV-diagnosed MSM in the United States: a meta-analysis. AIDS 2009;23:1617-29.

8. Sullivan PS, Hamouda 0, Delpech V, et al. Reemergence of the HIV epidemic among men who have sex with men in North America, Western Europe, and Australia, 1996-2005. Ann Epidemiol 2009:19:423-31.

9. Guenther-Grey C, Varnell S, Weiser J, et al. Trends in sexual risk-taking among urban young men who have sex with men, 1999-2002. J Natl Med Assoc 2005;97(7 Suppl):38S-43S.

10. Prestage G, Kippax $S$, Jin $F$, et al. Does age affect sexual behaviour among gay men in Sydney, Melbourne and Brisbane, Australia? AIDS Care 2009;21:1098-105.

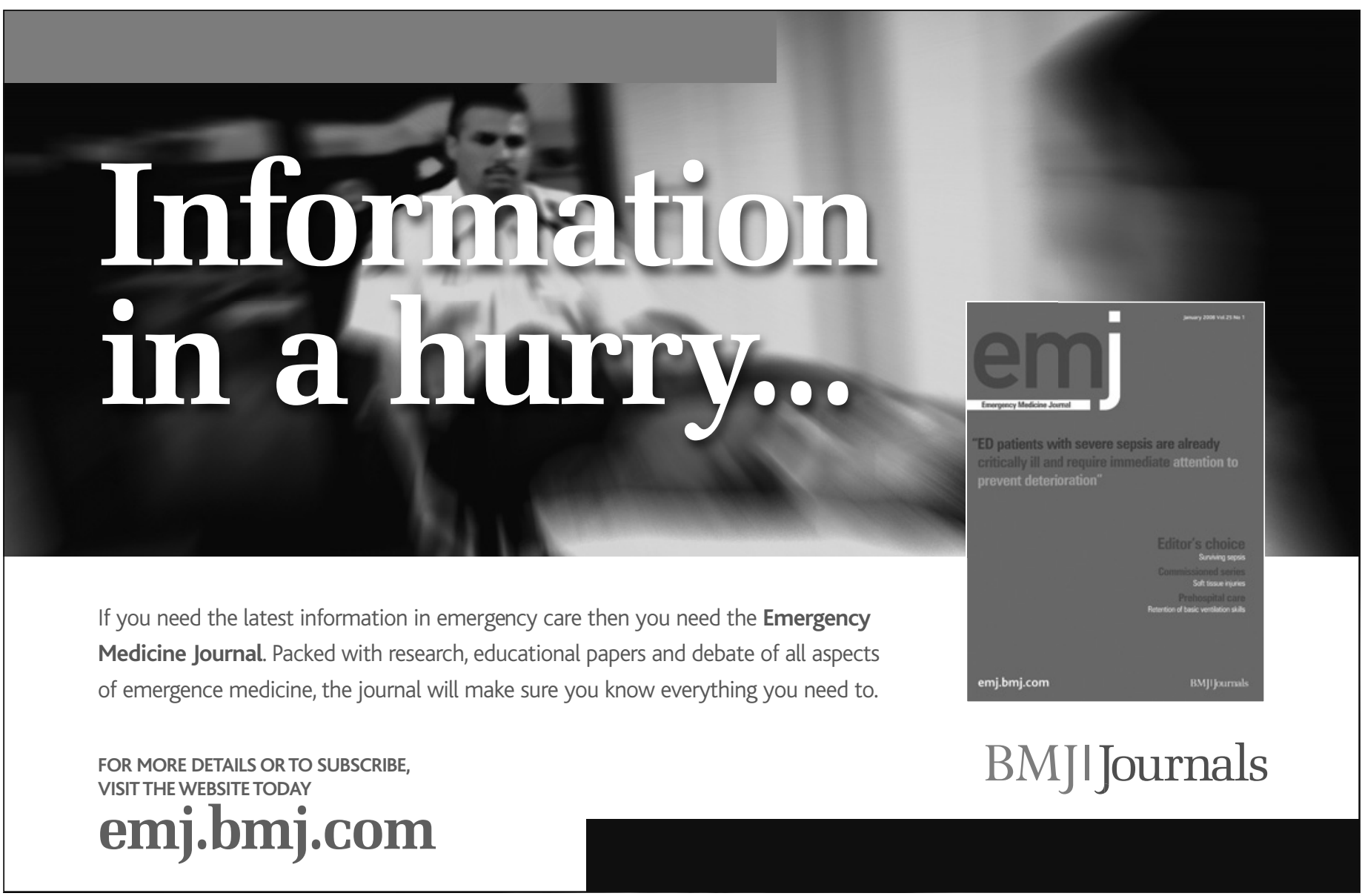

